\title{
Stability of Fixed Point Sets of a Class of Multivalued Nonlinear Contractions
}

\author{
Binayak S. Choudhury and Chaitali Bandyopadhyay \\ Department of Mathematics, Indian Institute of Engineering Science and Technology, Shibpur, Howrah 711103, India \\ Correspondence should be addressed to Chaitali Bandyopadhyay; chaitali.math@gmail.com
}

Received 29 July 2015; Revised 8 September 2015; Accepted 13 September 2015

Academic Editor: Alfred Peris

Copyright (C) 2015 B. S. Choudhury and C. Bandyopadhyay. This is an open access article distributed under the Creative Commons Attribution License, which permits unrestricted use, distribution, and reproduction in any medium, provided the original work is properly cited.

\begin{abstract}
We consider a problem of stability of fixed point sets for a sequence of multivalued mappings defined on a metric space converging to a limit function where the convergence is with respect to the Pompeiu-Hausdorff distance. The members of the sequence are assumed to be multivalued almost contractions. We show that the fixed point sets of this sequence of mappings are stable.
\end{abstract}

\section{Introduction and Preliminaries}

There are various notions of stability, both in discrete and continuous dynamical systems $[1,2]$. It is a concept in dynamical system related to limiting behaviors. In this paper we consider a problem of stability related to a sequence of multivalued mappings on metric spaces. The limiting behaviors of sequences of mappings have been considered in a number of papers in recent time as, for instances, in [3-5] the chaotic behavior under uniform convergence is investigated. Particularly, stability of fixed point sets has been considered in $[6-10]$.

Here our interest is in the stability of fixed point sets for a convergent sequence of multivalued mappings, that is, how they are related, in the limit, to the fixed point set of the function to which the sequence converges. We say that the fixed point sets are stable when they converge in the Pompeiu-Hausdorff distance to the set of fixed points of the limiting function. More often than not, in the above mentioned problem of stability, sequences of multivalued mappings are considered. One of the reasons behind this is that multivalued mappings often have more fixed points than their single valued counterparts. For instance, in the theorem of Nadler Jr. [3], which is the multivalued generalization of the Banach contraction principle and, incidentally, which is also the first work appearing on multivalued contractive fixed point studies, the fixed point is not unique in contrast to the case of single valued Banach's contractions in complete metric spaces. In those situations the fixed point set becomes larger and, hence, more interesting for the study of stability.

Almost contractions are generalizations of Banach's contraction. It was introduced by Berinde [11, 12].

In this paper we study the stability problem of fixed point sets for a uniformly convergent sequence of set valued almost contractions.

The following are some concepts, definitions, and results based on which we develop our main results.

Let $(X, d)$ be a metric space and let $C B(X)$ be the class of nonempty closed and bounded subsets of $X$. For $A, B \in$ $C B(X)$, functions $D(A, B)$ and $\delta(A, B)$ are defined as follows:

$$
\begin{gathered}
D(A, B)=\inf \{d(a, b): a \in A, b \in B\} ; \\
\delta(A, B)=\sup \{d(a, b): a \in A, b \in B\} .
\end{gathered}
$$

If $A=\{a\}$, then we write $D(A, B)=D(a, B)$ and $\delta(A, B)=$ $\delta(a, B)$. Also in addition, if $B=\{b\}$, then $D(A, B)=d(a, b)$ and $\delta(A, B)=d(a, b)$. Obviously, $D(A, B) \leq \delta(A, B)$. For all $A, B, C \in C B(X)$, the definition of $\delta(A, B)$ yields the following $[13,14]$ clearly:

$$
\begin{aligned}
& \delta(A, B)=\delta(B, A) ; \\
& \delta(A, B) \leq \delta(A, C)+\delta(C, B) ; \\
& \delta(A, B)=0 \quad \text { iff } A=B=\{x\}, \text { for some } x \in X ; \\
& \delta(A, A)=\operatorname{diam} A=\sup \{d(x, y): x, y \in A\} .
\end{aligned}
$$


Let $(X, d)$ be a metric space and let $C B(X)$ be the family of all nonempty closed and bounded subsets of $X$. The PompeiuHausdorff distance [15] $H$ is defined on $C B(X)$ by

$$
H(A, B)=\max \left\{\sup _{x \in B} d(x, A), \sup _{x \in A} d(x, B)\right\},
$$

where $A, B \in C B(X)$ and $d(x, A)=\inf _{y \in A} d(x, y)$.

We recall that a sequence of functions $\left\{T_{n}\right\}, n=1,2,3, \ldots$, converges uniformly on $X$ to a function $T$ if for every $\varepsilon>0$ there is an integer $N$ such that $n \geq N$ implies $\left|T_{n}(x)-T(x)\right| \leq$ $\varepsilon$ for all $x \in X$.

Let $(X, d)$ be a metric space and let $P(X)$ be the family of all subsets of $X$. Let $T: X \rightarrow P(X)$ be a mapping; a fixed point $z \in X$ of $T$ is such that $z \in T z$.

We denote $F(T)$ as a set of all fixed points of $T$.

Our purpose is to establish a stability result for the fixed point sets for a sequence of generalized multivalued almost contractions. The fixed point set for such a contraction is nonempty by Theorem 2 which is a consequence of a recent result of Choudhury and Metiya [16]. Nontrivial examples of the contractions of the above type are provided in [16].

Definition 1. Let $(X, d)$ be a complete metric space. Let $T: X \rightarrow C B(X)$ be a multivalued mapping. $T$ is called generalized multivalued almost contraction if

$$
\begin{aligned}
& \delta(T x, T y) \leq \psi(\max \{d(x, y), D(x, T x), D(y, T y), \\
& \left.\left.\frac{D(x, T y)+D(y, T x)}{2}\right\}\right)+L \min \{D(x, T x), D(y, \\
& T y), D(x, T y), D(y, T x)\}
\end{aligned}
$$

for all $x, y \in X$, where $L \geq 0$ and $\psi:[0, \infty) \rightarrow[0, \infty)$ is a nondecreasing and continuous function with $\psi(t)<t$ for each $t>0$.

The above mappings actually belong weakly to Picard operators which have been considered in [17-21], for instance.

The following theorem is a consequence of a result of Choudhury and Metiya [16].

Theorem 2. Let $(X, d)$ be a complete metric space. Let $T$ : $X \rightarrow C B(X)$ be a generalized multivalued almost contraction; that is, $T$ satisfies

$$
\begin{aligned}
& \delta(T x, T y) \leq \psi(\max \{d(x, y), D(x, T x), D(y, T y), \\
& \left.\left.\frac{D(x, T y)+D(y, T x)}{2}\right\}\right)+L \min \{D(x, T x), D(y, \\
& T y), D(x, T y), D(y, T x)\} .
\end{aligned}
$$

Then T has a fixed point.

Nadler Jr. [3] established the following lemma.
Lemma 3 (see [3]). Let $(X, d)$ be a metric space and $A, B \in$ $C B(X)$. Let $q>1$. Then, for each $x \in A$, there exists $y \in B$ such that $d(x, y) \leq q H(A, B)$.

In fact, Choudhury and Metiya [16] proved the result noted in Theorem 2 in a partially ordered metric space with some additional order conditions. Here we work with a metric space having no ordering defined on it.

\section{Main Result}

Theorem 4. Let $(X, d)$ be a complete metric space and let $T_{1}, T_{2}: X \rightarrow C B(X)$ be two multivalued generalized almost contractions with the same $\psi$ and $L$, where $\psi$ satisfies the following additional condition: $\Phi(t)=\sum \psi^{n}(t)<\infty$ with $\Phi(t) \rightarrow 0$ as $t \rightarrow 0$. Then

$$
\begin{aligned}
& H\left(F\left(T_{1}\right), F\left(T_{2}\right)\right) \leq \Phi(q k), \text { where } \\
& \quad k=\sup _{x \in X} H\left(T_{1} x, T_{2} x\right), \quad q>1 \text { is any number. }
\end{aligned}
$$

Proof. By Theorem 2, $F\left(T_{1}\right)$ and $F\left(T_{2}\right)$ are nonempty.

Let $q>1$ be any number. By Lemma 3, for $x_{0} \in F\left(T_{1}\right)$, there exists $x_{1} \in T_{2} x_{0}$ such that

$$
d\left(x_{0}, x_{1}\right) \leq q H\left(T_{1} x_{0}, T_{2} x_{0}\right) \leq q k \quad[\text { by }(6)] .
$$

We construct a sequence $\left\{x_{n}\right\}$ as, for all $n \geq 1, x_{n+1} \in$ $T_{2} x_{n}$. Then

$$
d\left(x_{n+2}, x_{n+1}\right) \leq \delta\left(T_{2} x_{n+1}, T_{2} x_{n}\right) .
$$

By (4),

$$
\begin{aligned}
d & \left(x_{n+2}, x_{n+1}\right) \leq \psi\left(\operatorname { m a x } \left\{d\left(x_{n+1}, x_{n}\right),\right.\right. \\
& D\left(x_{n+1}, T_{2} x_{n+1}\right), D\left(x_{n}, T_{2} x_{n}\right), \\
& \left.\frac{\left.\left.D\left(x_{n+1}, T_{2} x_{n}\right)+D\left(x_{n}, T_{2} x_{n+1}\right)\right\}\right)+L}{2}\right\} \\
& \cdot \min \left\{D\left(x_{n+1}, T_{2} x_{n+1}\right), D\left(x_{n}, T_{2} x_{n}\right), D\left(x_{n+1},\right.\right. \\
& \left.\left.T_{2} x_{n}\right), D\left(x_{n}, T_{2} x_{n+1}\right)\right\} \\
\leq & \psi\left(\operatorname { m a x } \left\{d\left(x_{n+1}, x_{n}\right), d\left(x_{n+1}, x_{n+2}\right), d\left(x_{n}, x_{n+1}\right),\right.\right. \\
& \left.\left.\frac{d\left(x_{n}, x_{n+2}\right)}{2}\right\}\right) \\
& {\left[\operatorname{since} x_{n+1} \in T_{2} x_{n}, \text { we have } D\left(x_{n+1}, T_{2} x_{n}\right)=0\right] } \\
\leq & \left(\operatorname { m a x } \left\{d\left(x_{n+1}, x_{n}\right), d\left(x_{n+1}, x_{n+2}\right),\right.\right. \\
& \left.\left.\frac{d\left(x_{n+1}, x_{n}\right)+d\left(x_{n+2}, x_{n+1}\right)}{2}\right\}\right) .
\end{aligned}
$$

It then follows that, for all $n \geq 1$,

$$
d\left(x_{n+2}, x_{n+1}\right) \leq \psi\left(d\left(x_{n}, x_{n+1}\right)\right) .
$$


Then by repeated application we have

$$
d\left(x_{n+2}, x_{n+1}\right) \leq \psi^{n+1}\left(d\left(x_{0}, x_{1}\right)\right) \leq \psi^{n+1}(q k)
$$

[by (7)] .

Therefore,

$$
\begin{aligned}
\sum d\left(x_{n+2}, x_{n+1}\right) & \leq \sum \psi\left(d\left(x_{n}, x_{n+1}\right)\right) \\
& \leq \sum \psi^{n}\left(d\left(x_{0}, x_{1}\right)\right) \leq \sum \psi^{n}(q k) \\
& <\infty .
\end{aligned}
$$

This implies that $\left\{x_{n}\right\}$ is a Cauchy sequence.

Since $(X, d)$ is complete, $\left\{x_{n}\right\} \rightarrow z$ as $n \rightarrow \infty$. Consider

$$
\begin{aligned}
& d\left(x_{n+1}, T_{2} z\right) \leq \delta\left(T_{2} x_{n}, T_{2} z\right) \leq \psi\left(\operatorname { m a x } \left\{d\left(x_{n}, z\right),\right.\right. \\
& D\left(x_{n}, T_{2} x_{n}\right), D\left(z, T_{2} z\right), \\
& \left.\left.\frac{D\left(z, T_{2} x_{n}\right)+D\left(x_{n}, T_{2} z\right)}{2}\right\}\right)+L \min \left\{D \left(x_{n},\right.\right. \\
& \left.\left.T_{2} x_{n}\right), D\left(z, T_{2} z\right), D\left(x_{n}, T_{2} z\right), D\left(z, T_{2} x_{n}\right)\right\} \\
& \leq \psi\left(\operatorname { m a x } \left\{d\left(x_{n}, z\right), d\left(x_{n}, x_{n+1}\right), D\left(z, T_{2} z\right),\right.\right. \\
& \left.\left.\frac{D\left(x_{n}, T z\right)+d\left(z, x_{n+1}\right)}{2}\right\}\right)+L \min \left\{d\left(x_{n}, x_{n+1}\right),\right. \\
& \left.D\left(z, T_{2} z\right), D\left(x_{n}, T z\right), d\left(z, x_{n+1}\right)\right\} .
\end{aligned}
$$

Taking limit $n \rightarrow \infty$ in the above inequality and from the properties of $\psi$, we have

$$
\begin{aligned}
d\left(z, T_{2} z\right) & \leq \psi\left(D\left(z, T_{2} z\right)\right) \leq \psi\left(d\left(z, T_{2} z\right)\right) \\
& <d\left(z, T_{2} z\right)
\end{aligned}
$$

which implies $d\left(z, T_{2} z\right)=0$. Since $T_{2}(z)$ is closed, so $z \in$ $F\left(T_{2}\right)$.

Now using triangular inequality we have

$$
\begin{aligned}
d\left(x_{0}, z\right) & \leq \sum_{i=0}^{n} d\left(x_{i}, x_{i+1}\right)+d\left(x_{n+1}, z\right) \\
& \leq \sum_{i=0}^{\infty} d\left(x_{i}, x_{i+1}\right) \quad[\text { taking } i \longrightarrow \infty] \\
& \leq \sum_{i=0}^{\infty} \psi^{i}\left(d\left(x_{0}, x_{1}\right)\right) \\
& \leq \sum_{i=0}^{\infty} \psi^{i}(q k)=\Phi(q k)<\infty .
\end{aligned}
$$

Thus, given arbitrary $x_{0} \in F\left(T_{1}\right)$, we can find $z \in F\left(T_{2}\right)$ for which

$$
d\left(x_{0}, z\right) \leq \Phi(q k)
$$

Reversing the roles of $T_{1}$ and $T_{2}$ we also conclude that, for each $y_{0} \in F\left(T_{2}\right)$, there exist $y_{1} \in T_{1}\left(y_{0}\right)$ and $w \in F\left(T_{1}\right)$ such that $d\left(y_{0}, w\right) \leq \Phi(q k)$.

From the above and from the definition of the PompeiuHausdorff distance, we conclude that

$$
H\left(F\left(T_{1}\right), F\left(T_{2}\right)\right) \leq \Phi(q k)
$$

This completes the proof.

Lemma 5. If $\left\{T_{n}\right\}$ is a sequence of multivalued generalized almost contractions which is uniformly convergent to $S$, then $S$ is a multivalued generalized almost contraction.

Proof. Since each $T_{n}$ is multivalued generalized almost contraction, therefore

$$
\begin{aligned}
& \delta\left(T_{n} x, T_{n} y\right) \leq \psi\left(\operatorname { m a x } \left\{d(x, y), D\left(x, T_{n} x\right),\right.\right. \\
& \left.\left.D\left(y, T_{n} y\right), \frac{D\left(x, T_{n} y\right)+D\left(y, T_{n} x\right)}{2}\right\}\right)+L \\
& \cdot \min \left\{D\left(x, T_{n} x\right), D\left(y, T_{n} y\right), D\left(x, T_{n} y\right), D(y,\right. \\
& \left.\left.T_{n} x\right)\right\} .
\end{aligned}
$$

Now, taking limit $n \rightarrow \infty$ we get

$$
\begin{gathered}
\delta(S x, S y) \leq \psi(\max \{d(x, y), D(x, S x), D(y, S y), \\
\left.\left.\frac{D(x, S y)+D(y, S x)}{2}\right\}\right)+L \min \{D(x, S x), D(y,
\end{gathered}
$$

$S y), D(x, S y), D(y, S x)\}$,

hence the result.

Theorem 6. If $\left\{T_{n}\right\}$ is a sequence of multivalued generalized almost contractions which is uniformly convergent to $S$, then the fixed point sets of $T_{n}$ are stable; that is,

$$
H\left(F\left(T_{n}\right), F(S)\right) \longrightarrow 0 \text { as } n \longrightarrow \infty
$$

Proof. $\left\{T_{n}\right\}$ converges to $S$ uniformly on $X$.

Therefore, by Lemma $5, S$ is a multivalued generalized almost contraction.

Let $k_{n}=\sup _{x \in X} H\left(T_{n} x, S x\right)$.

Since $T_{n} \rightarrow S$ uniformly with respect to the Pompeiu-Hausdorff distance, therefore $\lim _{n \rightarrow \infty} k_{n}=$ $\lim _{n \rightarrow \infty} \sup _{x \in X} H\left(T_{n} x, S x\right)=0$.

Then, from Theorem 4 , we obtain

$$
\begin{aligned}
& H\left(F\left(T_{n}\right), F(S)\right) \leq \Phi\left(q k_{n}\right) \longrightarrow 0 \\
& \text { as } n \longrightarrow \infty[\text { since } \Phi(t) \longrightarrow 0 \text { as } t \longrightarrow 0]
\end{aligned}
$$

This proves the theorem. 
Example 7. Let $X=[1,2]$, and $d$ is usual metric on $X$. Let $T_{n}: X \rightarrow C B(X)$ be defined as follows:

$$
T_{n} x=\left[x+\frac{1}{x}-\frac{1}{n}-\frac{1}{2}, 2\right], \quad \forall x \in X
$$

Let $\psi:[0, \infty) \rightarrow[0, \infty)$ be defined by

$$
\psi(t)=k t, \quad \text { where } t \in[0, \infty), \frac{3}{4} \leq k<1 .
$$

Let $L=1$. Then $T_{n}$ is multivalued generalized almost contraction.

Also we observe that $T_{n} \rightarrow T$ as $n \rightarrow \infty$, where $T x=$ $[x+1 / x-1 / 2,2]$.

Now for all $x \in X T_{1} x=[x+1 / x-3 / 2,2]$, and $T_{2} x=$ $[x+1 / x-1,2]$, for all $x \in X$.

Therefore we have $F\left(T_{1}\right)=[2 / 3,2]$ and $F\left(T_{2}\right)=[1,2]$. One has $H\left(F\left(T_{1}\right), F\left(T_{2}\right)\right)=1 / 3$. Consider

$$
\begin{aligned}
M & =\sup _{x \in X} H\left(T_{1} x, T_{2} x\right)=\frac{1}{2}, \\
\sum_{i=0}^{\infty} \psi^{i}(q M) & =\sum_{i=0}^{\infty} k^{n} q M=\frac{q M}{1-k}=\frac{q}{2(1-k)} .
\end{aligned}
$$

Let $q=2$; then $H\left(F\left(T_{1}\right), F\left(T_{2}\right)\right)=1 / 3 \leq q / 2(1-k)$. $F(T)$.

It is also observed that $F\left(T_{n}\right)=[2 n /(n+2), 2]$ and $\{2\}=$

Hence we conclude that $F\left(T_{n}\right) \rightarrow F(T)$ as $n \rightarrow \infty$ with respect to Pompeiu-Hausdorff distance. Then all of the conditions of Theorems 4 and 6 are satisfied which verify the above example.

\section{Conflict of Interests}

The authors declare that there is no conflict of interests regarding the publication of this paper.

\section{References}

[1] C. Robinson, Dynamical Systems: Stability, Symbolic Dynamics, and Chaos, CRC Press, 2nd edition, 1998.

[2] S. Strogatz, Nonlinear Dynamics and Chaos: With Applications to Physics, Biology, Chemistry, and Engineering, Westview Press, 2001.

[3] S. Nadler Jr., "Sequences of contractions and fixed points," Pacific Journal of Mathematics, vol. 27, no. 3, pp. 579-585, 1968.

[4] J. T. Markin, "Continuous dependence of fixed point sets," Proceedings of the American Mathematical Society, vol. 38, no. 3, pp. 545-545, 1973.

[5] I. Bhaumik and B. S. Choudhury, "Uniform convergence and sequence of maps on a compact metric space with some chaotic properties," Analysis in Theory and Applications, vol. 26, no. 1, pp. 53-58, 2010.

[6] J. T. Markin, "A fixed point stability theorem for nonexpansive set valued mappings," Journal of Mathematical Analysis and Applications, vol. 54, no. 2, pp. 441-443, 1976.

[7] G. Moţ and A. Petruşel, "Fixed point theory for a new type of contractive multivalued operators," Nonlinear Analysis, Theory, Methods and Applications, vol. 70, no. 9, pp. 3371-3377, 2009.
[8] T.-C. Lim, "On fixed point stability for set-valued contractive mappings with applications to generalized differential equations," Journal of Mathematical Analysis and Applications, vol. 110, no. 2, pp. 436-441, 1985.

[9] B. S. Choudhury and C. Bandyopadhyay, "A new multivalued contraction and stability of its fixed point sets," Journal of the Egyptian Mathematical Society, vol. 23, no. 2, pp. 321-325, 2015.

[10] B. S. Choudhury, N. Metiya, T. Som, and C. Bandyopadhyay, "Multivalued fixed point results and stability of fixed point sets in metric spaces," Facta Universitatis Series: Mathematics and Informatics, vol. 30, no. 4, pp. 501-512, 2015.

[11] V. Berinde, "Approximating fixed points of weak contractions using the Picard iteration," Nonlinear Analysis Forum, vol. 9, no. 1, pp. 43-53, 2004.

[12] V. Berinde, "General constructive fixed point theorems for Ciric type almost contractions in metric spaces," Carpathian Journal of Mathematics, vol. 24, no. 2, pp. 10-19, 2008.

[13] B. Fisher, "Common fixed points of mappings and set-valued mappings," Rostocker Mathematisches Kolloquium, vol. 18, pp. 69-77, 1981.

[14] B. Fisher and K. Ise'ki, "Fixed points for set-valued mappings on complete metric spaces," Mathematica Japonica, vol. 28, pp. 639-646, 1983.

[15] V. Berinde and M. Pacurar, "The role of the Pompeiu-Hausdorff metric in fixed point theory," Creative Mathematics and Informatics, vol. 22, no. 2, pp. 143-150, 2013.

[16] B. S. Choudhury and N. Metiya, "Fixed point theorems for almost contractions in partially ordered metric spaces," Annali dell'Università di Ferrara, vol. 58, no. 1, pp. 21-36, 2012.

[17] I. A. Rus, "Picard operators and applications," Scientiae Mathematicae Japonicae, vol. 58, no. 1, pp. 191-219, 2003.

[18] I. A. Rus, "Heuristic introduction to weakly Picard operator theory," Creative Mathematics and Informatics, vol. 23, no. 2, pp. 243-252, 2014.

[19] I. A. Rus, A. Petrusel, and G. Petrusel, Fixed Point Theory, Cluj University Press, Cluj-Napoca, Romania, 2008.

[20] I. A. Rus, A. Petruşel, and M. A. Șerban, "Weakly Picard operators: equivalent definitions, applications and open problems," Fixed Point Theory, vol. 7, no. 1, pp. 3-22, 2006.

[21] I. A. Rus and M.-A. Şerban, "Basic problems of the metric fixed point theory and the relevance of a metric fixed point theorem," Carpathian Journal of Mathematics, vol. 29, no. 2, pp. 239-258, 2013. 


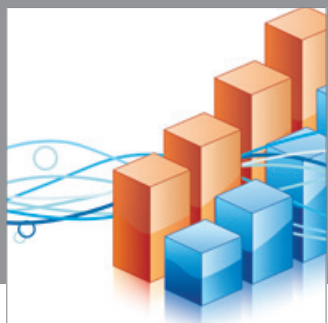

Advances in

Operations Research

mansans

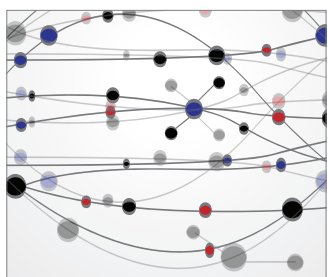

The Scientific World Journal
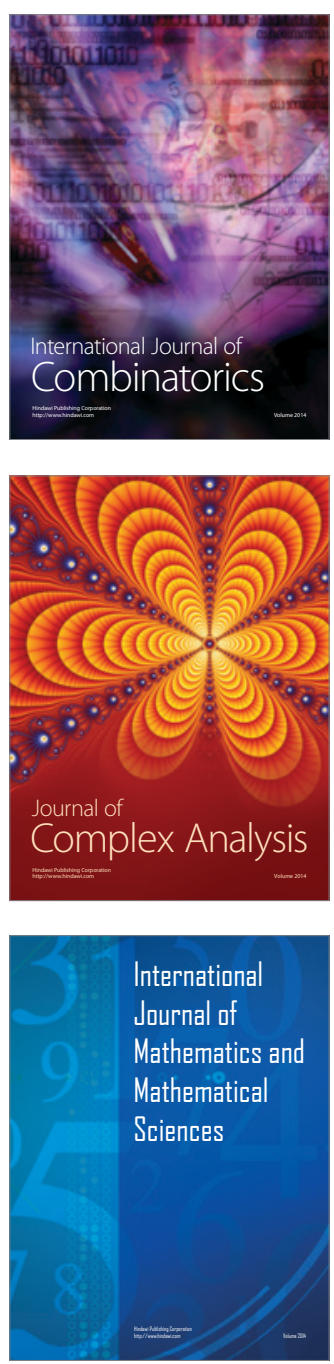
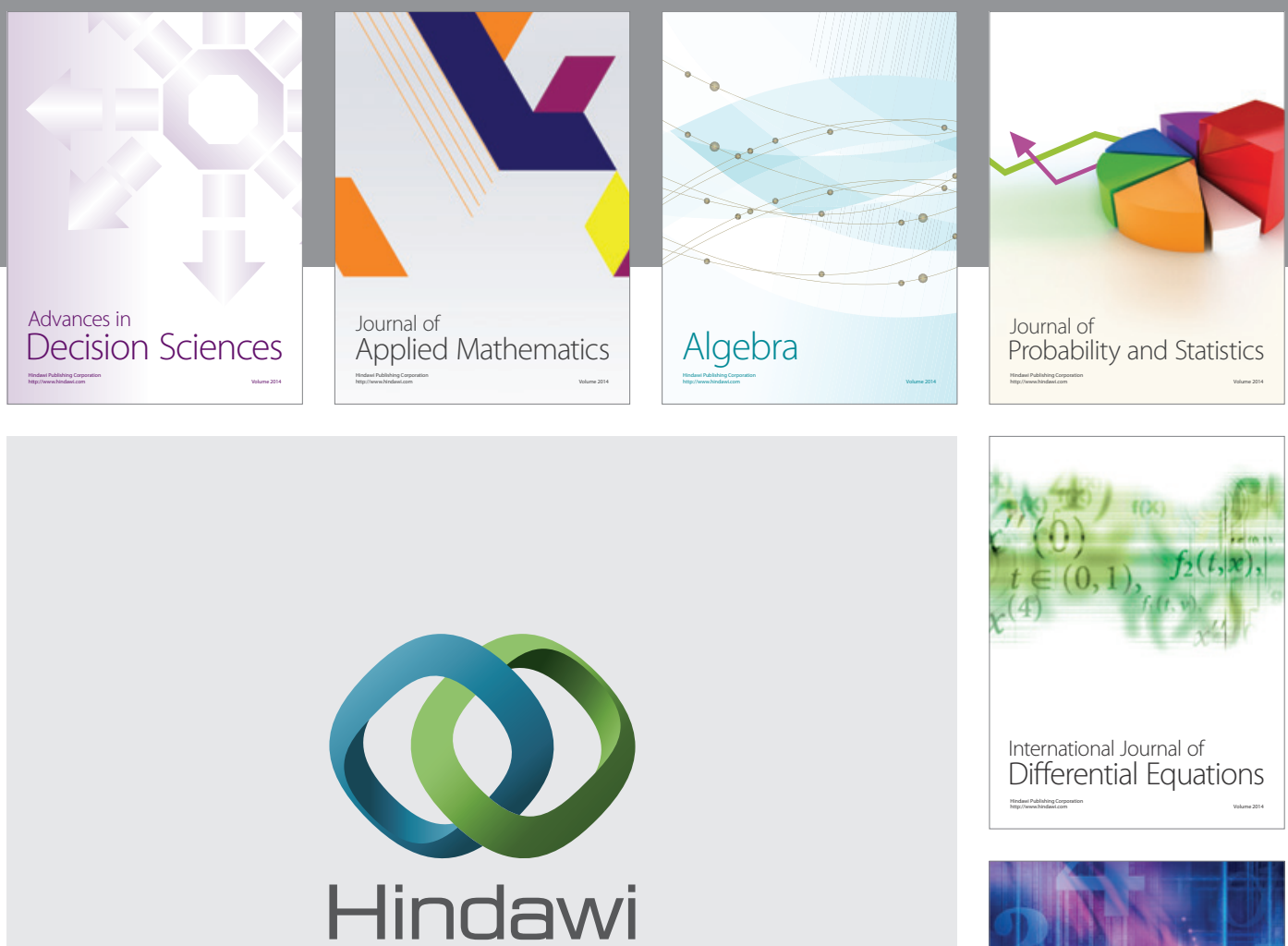

Submit your manuscripts at http://www.hindawi.com
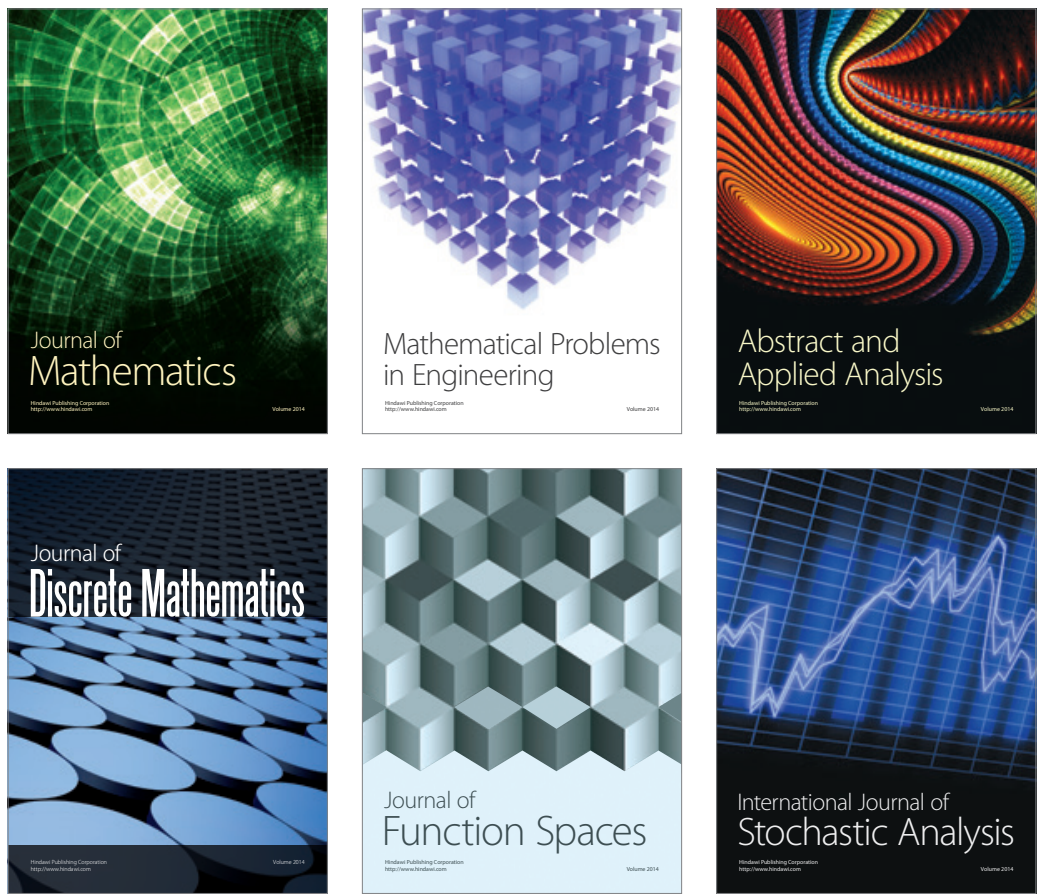

Journal of

Function Spaces

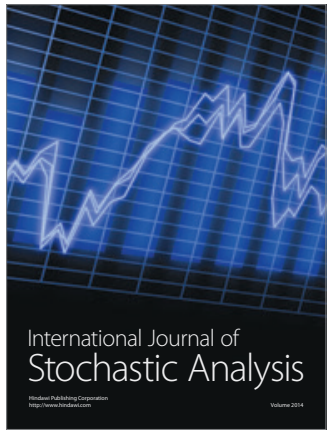

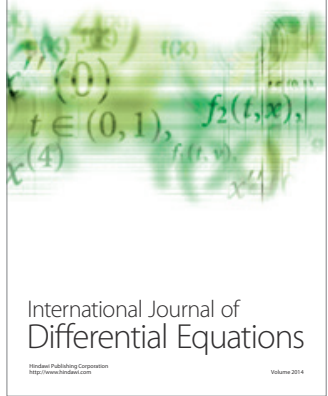
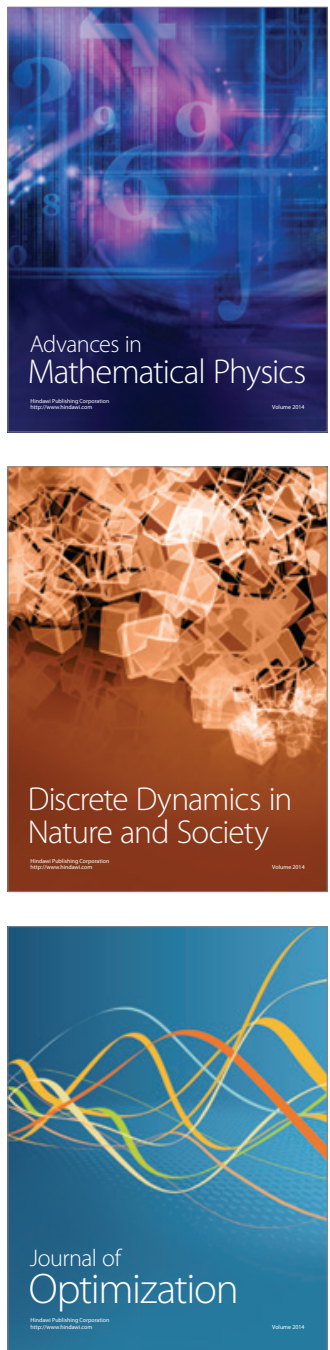